\title{
MICROSTRUCTURES AND STRUCTURAL DEFECTS IN HIGH-TEMPERATURE SUPERCONDUCTORS
}


This page is intentionally left blank 


\section{MICROSTRUCTURES AND STRUCTURAL DEFECTS IN HIGH-TEMPERATURE SUPERCONDUCTORS}

\section{Zhi-Xiong Cai \& Yimei Zhu \\ Brookhaven National Laboratory \\ Upton, New York, USA}




\section{Published by}

World Scientific Publishing Co. Pte. Ltd.

P O Box 128, Farrer Road, Singapore 912805

USA office: Suite 1B, 1060 Main Street, River Edge, NJ 07661

UK office: 57 Shelton Street, Covent Garden, London WC2H 9HE

\section{British Library Cataloguing-in-Publication Data}

A catalogue record for this book is available from the British Library.

\section{MICROSTRUCTURES AND STRUCTURAL DEFECTS IN HIGH-TEMPERATURE SUPERCONDUCTORS}

Copyright $\odot 1998$ by World Scientific Publishing Co. Pte. Ltd.

All rights reserved. This book, or parts thereof, may not be reproduced in any form or by any means, electronic or mechanical, including photocopying, recording or any information storage and retrieval system now known or to be invented, without written permission from the Publisher.

For photocopying of material in this volume, please pay a copying fee through the Copyright Clearance Center, Inc., 222 Rosewood Drive, Danvers, MA 01923, USA. In this case permission to photocopy is not required from the publisher.

ISBN $981-02-3285-3$

Printed in Singapore by Uto-Print 


\section{For \\ Danning and Eriko}


This page is intentionally left blank 


\section{Preface}

This book is geared toward upper-level undergraduate students and entry-level graduate students majoring in physics or materials science who are interested in crystal structure and structural defects, particularly those related to high-temperature superconductors. Researchers involved in studying high- $\mathrm{T}_{c}$ materials should also find the book useful as it consistently summarizes the recent progress in this field.

The book has an extensive introduction to microstructures and structural defects in high-temperature superconductors. It emphasizes the application of experimental as well as theoretical modeling techniques to the study of these complex materials, rather than simply presenting the results of current research. The reader is given an overview of the complexities in understanding structure-sensitive properties of bulk high- $\mathrm{T}_{c}$ materials, such as the transport properties, and in developing large-scale (high current, high field) applications. Whenever feasible, the effects of defects on the superconducting properties of these materials are described to put the study of the microstructure in a proper perspective.

We do not attempt to cover all aspects of high-temperature superconductivity research; instead, only the bare-bone knowledge of superconductivity theory is introduced. To link the structure to the properties, we focus on the interpretation of the microstructure and structural defects based on observations with advanced transmission electron microscopy coupled with theoretical modeling techniques. We illustrate experimental and theoretical techniques to study microstructures and structural defects with examples drew from various high- $\mathrm{T}_{c}$ superconductors. The usefulness of most of the techniques is not unique to 
viii

high-temperature superconductors; they can be easily applied to metals, ceramics, and other complex materials.

This book is mainly derived from our own researches, and is our joint effort. In Chapters 1 (Cai) we briefly review the history of research in high-temperature superconductivity. In Chapter 2 (Cai) we introduced the basic notion of superconductivity and its relationship to microstructure and defects, especially in high- $T_{c}$ superconductors. Chapter 3 (Cai and $\mathrm{Zhu}$ ) is an overview of experimental techniques and theoretical modeling, mainly those used in the researches described in this book to study defects in materials. Chapter 4 (Zhu and Cai) summarizes the crystal structure of three major families of high-temperature superconductors, the La-, Y-, and Bi-based cuprates. In Chapter 5 (Zhu), we introduce the basic notions of various types of defects, both intragranular and inter-granular that appear in superconducting oxides, and the geometrical approach (interfacial dislocations and Coincidence-SiteLattice model) to studying grain boundaries. In the following chapters, we discuss experimental and theoretical studies of various types of microstructural features and defects in high-temperature superconductors. Chapters 6 and 7 are devoted to oxygen disorder/order related defects in $\mathrm{YBa}_{2} \mathrm{Cu}_{3} \mathrm{O}_{7-\delta}$. Chapter 6 (Cai and $\mathrm{Zhu}$ ) describes in detail the "tweed" structure, a displacive modulation due to oxygen ordering, and its structural origin. Chapter 7 (Zhu) offers observations and interpretations of the atomic structures of twinning variants and varied twin boundaries, another type of oxygen ordering associated with highsymmetrical lattice planes in $\mathrm{YBa}_{2} \mathrm{Cu}_{3} \mathrm{O}_{7-\delta}$. Chapter 8 (Cai and $\mathrm{Zhu}$ ) discusses structural modulations and the related phase transformations in $\mathrm{La}_{2-x} \mathrm{Ba}_{x} \mathrm{O}_{4}$. Chapter 9 (Cai and Suenaga) covers the kinetics of grain alignment and formation of $\mathrm{Bi}-2223$ in $\mathrm{Bi}-2223 / \mathrm{Ag}$ tapes, which is very important to large-scale applications of the high- $\mathrm{T}_{c}$ superconductors. Chapter $10(\mathrm{Zhu})$ presented a novel diffraction technique to study charge distribution in $\mathrm{YBa}_{2} \mathrm{Cu}_{3} \mathrm{O}_{7-\delta}$ and $\mathrm{Bi}-2212$ superconductors. Chapter 11 (Zhu) and Chapter 12 (Zhu) extensively discuss the structure of grain boundaries. The former describes various experimental methods based on nano-probe electron microscopy that is required to study grain boundaries, such as determining boundary crystallography and measuring local hole concentration and lattice parameters. The latter provides a detailed account of grain boundary structure including 
misorientation distribution in practical Y-and Bi-based superconducting materials. We emphasize the correlation between the boundary hole concentration and the boundary lattice constraint for YBCO, and address the structure-property relation by examining the structure of the electromagnetically characterized $\mathrm{Bi}-2212$ bicrystals. In the last section (12.4) of the chapter (Cai), we propose a theoretical model for understanding superconductivity in polycrystalline materials. In Chapter 13 (Zhu, Sec.13.4: Cai) we present our study of columnar defects produced by heavy-ion irradiation, the effects of crystal orientation, stochiometry, and imperfection on these columnar defects, and their structural nature and formation mechanism. Brief conclusions are given in the final chapter (Cai), and suggestions made on the future directions of research.

We have tried to treat the subject in an elementary way. While the inclusion of some mathematical formulae is unavoidable, we have emphasized the physics, instead of fancy mathematical treatment. Thus, the reader needs only basic knowledge of statistical mechanics, solidstate physics and calculus to follow the discussions in this book.

It is our hope that this book will draw attention to the area of materials science in which fruitful researches are being conducted and in which many challenging problems remain.

This book has developed over a number of years of research in the Materials Science Division, Department of Applied Science at Brookhaven National Laboratory. We have benefited greatly from the input of our colleagues, visiting scientists, collaborators, students, and friends, who have directly and indirectly contributed to this book. In particular we wish to thank M. Suenaga and D.O. Welch, BNL, who encouraged us to take up this project, for their knowledge, and stimulating discussions. We thank J. Tafto, Univ. of Oslo, for his creative and fruitful contribution during his short but productive summer visits in the recent years. We gratefully acknowledge the generous assistance and cooperation of Q. Li, A.R. Moodenbaugh, R.L. Sabatini and L. Wu. We are also indebted to W. Bian, R.C. Budhani, Y. Corcoran, J. Cowley, Y. Fukumoto, A.G. Khachaturyan, A. King, T.R. Thurston, Y.N. Tsay, J.-Y. Wang, Y.-L. Wang, Z.L. Wang, H.J. Wiesmann, Y. Xu, H. Zhang and J.M. Zuo (in alphabetical order), who are the co-authors of our published researches. We thank F. Ling, Y. Koh, and S. Patt 
$\mathrm{x}$

from World Scientific Publishing Inc. for their help in preparing the manuscript. Last, but not least, we thank our families, Danning and Yida, and Eriko and Anna. This book would never have been written without their understanding and support.

Zhi-Xiong Cai

Yimei Zhu

Long Island, New York

February 1998 


\section{Contents}

Preface vi

1 Introduction 1

2 Defects and Superconductivity $\quad 7$

2.1 What is Superconductivity? . . . . . . . . . 7

2.2 The Electromagnetic Properties of Superconductor . . . 9

2.3 The London Model . . . . . . . . . . . . . . . . . . . 10

2.4 Ginzburg-Landau Theory . . . . . . . . . . . . . . . . . 14

2.5 Two Types of Superconductors . . . . . . . . . . . . 18

2.6 Critical Current in Type-II Superconductors . . . . . . . 23

2.7 Flux-line Pinning and Microstructure . . . . . . . . . . 24

2.8 Good and Bad Defects . . . . . . . . . . . . 25

3 Tools Used to Study the Defects 27

3.1 Introduction . . . . . . . . . . . . . . 27

3.2 Experimental Tools . . . . . . . . . . . . . . 27

3.2.1 Transmission Electron Microscopy . . . . . . . 27

3.2.2 X-ray and Neutron Diffraction . . . . . . . . 30

3.3 Theoretical Modeling and Computer Simulation . . . . . 31

3.3.1 Interaction Between Atoms . . . . . . . . . . 31

3.3.2 Computer Simulation . . . . . . . . . . . 34

4 The Structure Characteristics $\quad 41$

4.1 Introduction . . . . . . . . . . . . . . 41

4.2 Crystal Structure . . . . . . . . . . . . . 41

4.2.1 La214 and Related Structures . . . . . . . . . . 42

4.2.2 $\mathrm{YBa}_{2} \mathrm{Cu}_{3} \mathrm{O}_{7-\delta}(\mathrm{Y} 123)$ and Related Structures . . 44 
4.2.3 $\mathrm{Bi}_{2} \mathrm{Sr}_{2} \mathrm{Ca}_{n-1} \mathrm{Cu}_{n} \mathrm{O}_{2 n+6}$ and Related Structures . . 48

4.3 Bonding and Structural Features . . . . . . . . . 52

5 Types of Defects $\quad 55$

5.1 Intragranular Defects . . . . . . . . . . 55

5.1 .1 Point Defects . . . . . . . . . . . 55

5.1 .2 Line Defects-Dislocations . . . . . . . . . 58

5.1 .3 Planar Defects . . . . . . . . . . . 61

5.1.4 Volume Defects - Inclusions . . . . . . . . . . 62

5.1 .5 Structural Modulations . . . . . . . . . . . . 64

5.1.6 Artificially Created Defects . . . . . . . . 65

5.2 Intergranular Defects - Grain Boundaries . . . . . . . . 69

5.2.1 The Concept of Coincidence Site Lattice . . . . . 70

5.2.2 The Concept of O-lattice . . . . . . . . . . . . 72

5.2 .3 Frank Formula . . . . . . . . . . . . . 73

6 Oxygen Ordering Related Defects in $\mathrm{YBa}_{2} \mathrm{Cu}_{3} \mathrm{O}_{7} \quad \mathbf{7 5}$

6.1 Introduction . . . . . . . . . . . . 75

6.2 Models for Oxygen Ordering in $\mathrm{YBa}_{2} \mathrm{Cu}_{3} \mathrm{O}_{7-\delta} \ldots \ldots . .77$

6.3 Effect of Thermal Quenching on Oxygen Ordering . . . . 89

6.4 [110] Tweedy Modulation . . . . . . . . . . . 96

6.5 Theoretical Model for $\mathrm{Fe}$ Doped $\mathrm{YBa}_{2} \mathrm{Cu}_{3} \mathrm{O}_{7-\delta}$

and Tweed . . . . . . . . . . . . . . . 107

6.5.1 Model for Oxygen Ordering in $\mathrm{Fe}$ Doped $\mathrm{YBa}_{2} \mathrm{Cu}_{3} \mathrm{O}_{7-\delta} \ldots \ldots \ldots$. . . . . . . . . 107

6.5.2 Modification of the Lattice Gas Model to Include Elastic Strain . . . . . . . . . . . . . . 113

6.6 Reduction and Reoxidation in $\mathrm{YBa}_{2}\left(\mathrm{Cu}_{1-x} \mathrm{Fe}_{x}\right)_{3} \mathrm{O}_{7-\delta} \quad .120$

6.7 Three Dimensional Structural Modulation . . . . . . . . 131

$6.7 .10 .02<x<0.10 \ldots \ldots . \ldots . \ldots 131$

$6.7 .20 .10<x<0.33 \ldots \ldots . \ldots 134$

6.7.3 Simulation of Tweed Image Contrast . . . . . . . 142

6.8 Summary . . . . . . . . . . . . . . . 145

7 The Twin Boundary Structure in $\mathrm{YBa}_{2} \mathrm{Cu}_{3} \mathrm{O}_{7-\delta} \quad 147$

7.1 Introduction . . . . . . . . . . . . . . . . . . 147

7.2 Gross Features of the Twin Boundary . . . . . . . . . 149

7.2.1 Conventional TEM Observations . . . . . . . . 149 
7.2.2 HREM Observations . . . . . . . . . . . . 153

7.2.3 The Effects of Cation Substitution . . . . . . 156

7.2.4 The Effects on Superconducting Properties . . . . 159

7.3 Studies of the Displacement at the Twin Boundary . . . 160

7.3.1 Evolution of the Twin-Boundary Structure During Electron-Beam Irradiation . . . . . . . . . . . 160

7.3.2 The Variability of the Twin Boundaries . . . . . . 162

7.3.3 Analyses of Fringe Contrast of the Twin Boundary 166

7.3.4 Analyses of the Streaks of Diffuse Scattering . . 170

7.3.5 Interfacial Energy of the Twin Boundaries . . . . 174

7.4 Crystallographic Analysis of the Twin Boundary . . . . . 177

7.4.1 A $\Sigma 64$ Coincidence Boundary . . . . . . . . . 177

7.4.2 Twin-Boundary Steps and Twinning Dislocations . . . . . . . . . . . . . . . . . 179

7.4.3 A Displacement-Shift-Complete-Lattice (DSCL) Treatment . . . . . . . . . . . . . . 183

7.4.4 Structure of Mixed Twin Boundaries . . . . . . 185

7.5 Twin Tip . . . . . . . . . . . . . . . . . 188

7.5.1 Four Twinning Variants . . . . . . . . . . . . 190

7.5.2 The Shape of a Tapered Twin . . . . . . . . . 195

7.5.3 Interfaces of the Orthogonally Oriented Twins . . 199

7.6 Summary . . . . . . . . . . . . . . . . 201

8 Structural Modulation in $\mathrm{La}_{2-x} \mathrm{Ba}_{x} \mathrm{CuO}_{4}$

8.1 Introduction . . . . . . . . . . . . . . . 203

8.2 Consecutive Structural Transformation and Lattice Dynamical Model . . . . . . . . . . . . . . 205

8.3 Low-Temperature Microstructure . . . . . . . . . . 215

8.4 Theoretical Model of Twin Boundary Structure . . . . . 224

8.4.1 Landau Model . . . . . . . . . . . . . . . 225

8.4.2 The Structure of Twin Boundary . . . . . . . . . 227

8.4.3 The Size of the Twin Domains . . . . . . . . . . 233

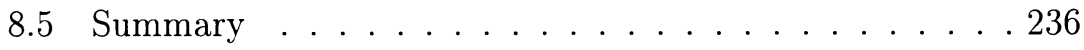

9 Kinetics of the Alignment and the Formation of $\mathrm{Bi}-2223$

9.1 Introduction . . . . . . . . . . . . . 237 
9.2 The Fabrication Procedure . . . . . . . . . . . . 241

9.3 Evolution at Early Stages of Heat Treatment . . . . . . . 244

9.3.1 In situ X-ray Diffraction Measurements . . . . . . 245

9.3.2 Electron Microscopy . . . . . . . . . . . . . . . 248

9.3.3 The Formation of Bi-2223 . . . . . . . . . 262

9.4 Dislocation and Bismuth 2212-to-2223 Transformation . 271

9.4.1 Introduction . . . . . . . . . . . . . . 271

9.4.2 Edge-dislocations as Channels for Fast Ion Diffusion . . . . . . . . . . . . . 274

9.4.3 The Layer Rigidity Model . . . . . . . . . . . . . 275

9.4.4 Kinetics of Bi-2212 Conversion to Bi-2223 . . . . 282

9.5 Summary . . . . . . . . . . . . . . . 287

10 Charge Distribution $\quad 289$

10.1 Introduction . . . . . . . . . . . . . . . . . 289

$10.2 \mathrm{Bi}_{2} \mathrm{Sr}_{2} \mathrm{CaCu}_{2} \mathrm{O}_{8} \ldots \ldots \ldots \ldots \ldots . \ldots \ldots 29 \ldots \ldots$

10.2.1 A General Nano-scale Description . . . . . . . . 292

10.2.2 Direct Imaging of Charge Modulation . . . . . . . 295

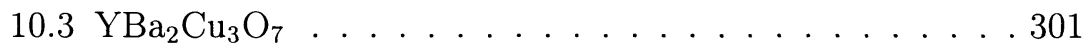

10.3.1 A Novel Diffraction Method . . . . . . . . . . 301

10.3.2 Distribution of Electron Holes . . . . . . . . . . 308

10.4 Conclusion . . . . . . . . . . . . . . . . . 312

11 Experimental Techniques for Grain Boundary Studies 313

11.1 Analyses of Grain Boundary Crystallography . . . . . . . 314

11.1.1 Determination of Grain Boundary Geometry . . . 314

11.1.2 Case Study of $\mathrm{YBa}_{2} \mathrm{Cu}_{3} \mathrm{O}_{7-\delta} \ldots \ldots$. . . . . . 320

11.2 Electron Energy-Loss Spectroscopy of Oxygen K-edge . . 328

11.2.1 Experimental Considerations of TEM-EELS . . . 329

11.2.2 Orientational Dependence of the Oxygen Pre-peak . . . . . . . . . . . . . . 334

11.2.3 Quantitative Analysis of Oxygen/hole Concentration . . . . . . . . . . . . 337

11.3 Lattice Parameter from CBED Measurement of HOLZ

Pattern . . . . . . . . . . . . . . 340 
12 The Structure of Grain Boundaries 345

12.1 Introduction . . . . . . . . . . . . . . . . . 345

12.2 Grain Boundaries in $\mathrm{YBa}_{2} \mathrm{Cu}_{3} \mathrm{O}_{7-\delta} \ldots \ldots$. . . . . 346

12.2.1 Misorientation Distribution in Textured Bulks . . 347

12.2.2 Grain Boundary Dislocations . . . . . . . . . . 352

12.2.3 Oxygen Content and CCSL Boundaries . . . . . . 355

12.2.4 Variation of Oxygen/hole at the Boundaries . . . 358

12.2.5 Cation Segregation at the Boundary . . . . . . 368

12.2.6 Strain Energy of the Grain Boundaries . . . . . . 371

12.3 Grain Boundaries in $\mathrm{Bi}_{2} \mathrm{Sr}_{2} \mathrm{CaCu}_{2} \mathrm{O}_{8+\delta} \ldots \ldots . . . .376$

12.3.1 Misorientation Distribution in $\mathrm{Bi}-2212$ and $\mathrm{Bi}$ 2223 Composite Tapes . . . . . . . . . . . 378

12.3.2 Superconducting Properties of Twist Boundaries

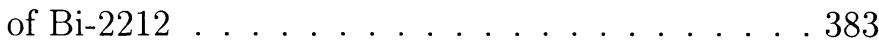

12.3.3 Structural Features of the Twist Boundaries . . . 387

12.4 RSJ Model . . . . . . . . . . . . . . . . 403

12.5 Summary . . . . . . . . . . . . . . . . 417

13 Artificially Created Defects $\quad 419$

13.1 Introduction . . . . . . . . . . . . . . . . . 419

13.2 Experimental Methods . . . . . . . . . . . . . 420

13.2.1 Sample Preparation . . . . . . . . . . . . . 420

13.2.2 Heavy-ion Irradiation . . . . . . . . . . . . . . .421

13.3 Structure of the Defects . . . . . . . . . . . . . . . 421

13.3.1 General Morphology . . . . . . . . . . . . . . 421

13.3.2 Radiation Damage Induced by $\mathrm{Au}, \mathrm{Ag}, \mathrm{Cu}$, and Si Ions . . . . . . . . . . . . . . . . . . 424

13.3.3 The Effect of Crystallographic Orientation . . . . 430

13.3.4 The Effects of Oxygen Concentration in $\mathrm{YBa}_{2} \mathrm{Cu}_{3} \mathrm{O}_{7-\delta} \ldots \ldots \ldots \ldots . \ldots . \ldots . \ldots 41$

13.3.5 The Effect of the Pre-existing Crystal Imperfections 435

13.3.6 Creation of Stacking Faults . . . . . . . . . . . . . 437

13.3.7 EELS Measurements . . . . . . . . . . . . . 439

13.4 Thermal Spike Model . . . . . . . . . . . . . . . . . 441

13.4.1 Stopping Power of Heavy Ions . . . . . . . . . . . 442

13.4.2 The Size of the Defect Area . . . . . . . . . . . . 443

13.4.3 Anisotropy of the Size and Shape of the Defects . 448 
13.5 Strain Field and Strain Contrast of Columnar Defects . . 450 13.5.1 The Displacement Fields of Columnar Defects . . 451

13.5.2 Intensity of the Diffraction Contrast of the Columnar Defects . . . . . . . . . . . . 455

13.5.3 Simulation of the Strain Contrast of the Columnar Defects . . . . . . . . . . . . . 4 457

13.5.4 The Radial Displacement and Strain of the Columnar Defects . . . . . . . . . . . . . . 462

13.6 Planar Defects Induced by Heavy-ion Irradiation . . . . . 465 13.6.1 Morphology of the Planar Defects . . . . . . . . . 465

13.6.2 Microchemical Analysis of the Planar Defects . . 467 13.6.3 Structure of the Planar Defects . . . . . . . . . . 469

13.7 Summary . . . . . . . . . . . . . . . 4 474

14 Conclusions

Bibliography

Index 